\title{
Substituent Effects in the Mass Spectra of Benzoyl Hetarenes $\dagger$
}

\author{
Hans-Fr. Grützmacher $\ddagger$ and Ralf Schubert \\ Fakultät für Chemie, Universität Bielefeld, Universitätsstraße, D-4800 Bielefeld 1, W. Germany
}

\begin{abstract}
The mass spectra of several benzoyl hetarenes, of 2-benzoyl pyridines substituted at the phenyl and pyridyl group, respectively, and of phenyl substituted 2-benzoyl pyrroles, have been studied with respect to the formation of benzoyl and hetaroyl ions. A correlation between the intensity of benzoyl ions, relative to molecular ion intensity, and the $\pi$-electron density at the substituted carbon atom of the hetarene has been observed for benzoyl hetarenes. The relative intensities of (substituted) benzoyl ions of substituted 2-benzoyl pyridines and 2-benzoyl pyrroles are not easily related to substituent constants of Hammett equations. The relative ionization energies of phenyl substituted 2-benzoyl pyridines, however, and the relative appearance energies of substituted benzoyl ions derived therefrom follow the $\sigma_{\mathrm{IP}}{ }^{+}$-constant of Bentley and Johnstone and the $\sigma^{+}$-constants of Brown, respectively.
\end{abstract}

The mass spectra of benzophenones and the polar ${ }^{2}$ and steric $^{3}$ effects of substituents on their fragmentation reactions have received much attention, especially with respect to the formation of (substituted) benzoyl ions. Much less is known about the mass spectrometric behaviour of the related hetaryl ketones, ${ }^{4}$ which have been investigated mainly because of certain rearrangement reactions of the molecular ions. ${ }^{5}$ In the course of an investigation of these rearrangement reactions we have synthesized a number of hetaryl phenyl ketones and a series of substituted 2-benzoyl pyridines. These substances can form (substituted) benzoyl ions $a$ as well as (substituted) hetaroyl ions $b$ in their $70 \mathrm{eV}$ mass spectra, and we report here some mass spectrometric data relevant to the question of whether similar regularities observed for the formation of $a$ in the mass spectra of benzophenones ${ }^{2}$ are also found for these hetaryl ketones.

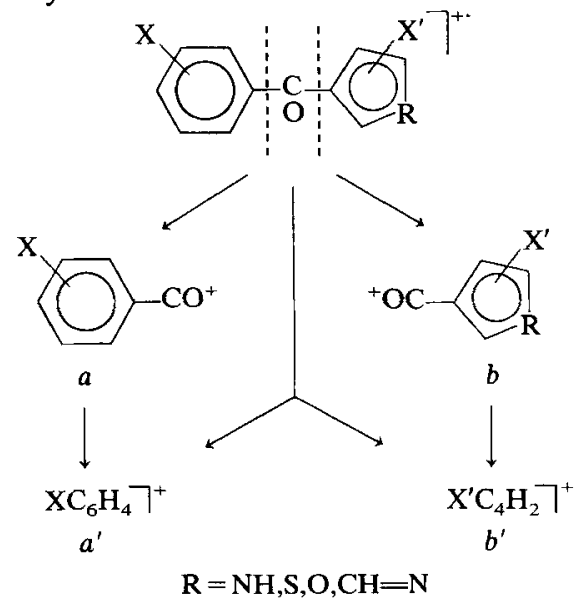

\section{Benzoyl hetarenes}

In this series benzophenone (1) as reference, 2-benzoylpyridine (2), 3-benzoylpyridine (3), 4benzoylpyridine (4), 2-benzoylpyrazine (5), 4-

$\dagger$ See Ref. 1.

¥ Author to whom correspondence should be addressed. benzoylpyrimidine (6), 2-benzoylfuran (7), 2benzoylthiophene (8) and 2-benzoylpyrrole (9) have been investigated. The relative intensities of the ions $a, a^{\prime}, b$ and $b^{\prime}$, the ionization energies $I(\mathrm{M})$ of the molecular ions and the appearance energies $A\left(\mathrm{~F}^{+}\right)$of the fragment ions $a$ and $b$ are given in Table 1 and Table 2 , respectively. No attempt was made to differentiate between ions $a^{\prime}$ and $b^{\prime}$ formed directly from the molecular ions and those formed from the ions $a$ and $b$ respectively.

The variation in the $I(M)$ of the benzoyl hetarenes corresponds to the trend observed in the $I(M)^{6 a}$ of benzene $(9.25 \mathrm{eV})$, pyridine $(9.27 \mathrm{eV})$, pyrazine $(9.29 \mathrm{eV})$, pyrimidine $(9.35 \mathrm{eV})$, furan $(8.89 \mathrm{eV})$, thiophene $(8.87 \mathrm{eV})$ and pyrrole $(8.21 \mathrm{eV})$. The $I(\mathbf{2})$, however, seems to be too low. From substituent effects on the $I(\mathrm{M})$ of pyridine $\mathrm{e}^{6 \mathrm{~b}}$ the $I(\mathrm{M})$ of 2,3 and 4 are calculated to $9.56 \mathrm{eV}, 9.70 \mathrm{eV}$ and $9.78 \mathrm{eV}$, respectively. The activation energies for the formation of $a$, expressed as $A(a)-I(M)$, decreases in 1-5 and 6 and increases in 7, 8 and 9 . The activation energies of the formation of $b$ are also quite large in the latter compounds. This is due partly to lowering of the $I(\mathrm{M})$ and is also reflected in an increase in the intensity of the molecular ions.

With the exception of 2, which shows large peaks of $[\mathrm{M}-\mathrm{H}]^{+},[\mathrm{M}-\mathrm{CO}]^{+-}$and $[\mathrm{M}-\mathrm{CHO}]^{+}$ions $^{5 \mathrm{a}}$ in its mass spectrum, the ions of Table 1 represent $>85 \%$ of the total ion current above $m / z 60$.

As was noted earlier, ${ }^{3}$ the benzoyl pyridines 2,3 and 4 do not form pyridoyl ions $b$ with large abundances in their $70 \mathrm{eV}$ mass spectra. Similarly, at $70 \mathrm{eV}$ the intensities of ions $b$ are very low in the mass spectra of the benzoyl diazines 5 and $\mathbf{6}$, the benzoyl ion a dominating the spectra. However, this behaviour is changed in benzoyl derivatives 7,8 and 9 of hetarenes with 5 -membered rings, as indicated by the increasing value of the intensity ratio $b / a$. Similarly, the intensity ratio $b+b^{\prime} / a+a^{\prime}$, indicating preferred charge retention by the fragments of the hetaryl moiety of the molecular ions, increases in the series. The 
Table 1. Relative intensities ${ }^{\mathrm{a}}$ of fragment ions of benzoyl hetarenes

\begin{tabular}{|c|c|c|c|c|c|c|c|c|c|}
\hline Compound & Base peak & {$[\mathbf{M}]^{+*}$} & $a$ & $a^{\prime}$ & b & $b^{\prime}$ & $b / a$ & $\frac{b+b^{\prime}}{a+a^{\prime}}$ & Remarks \\
\hline 1 & {$\left[\mathrm{M}-\mathrm{C}_{6} \mathrm{H}_{5}\right]^{+}$} & 58 & 100 & 44 & - & - & - & - & {$[M-H]^{+} 7$} \\
\hline 2 & {$\left[\mathrm{M}-\mathrm{C}_{6} \mathrm{H}_{4} \mathrm{NO}^{+}\left(\mathrm{a}^{\prime}\right)\right.$} & 32 & 85 & 100 & $<1$ & 12 & $<0.01$ & 0.06 & $\begin{array}{l}{[\mathrm{M}-\mathrm{H}]^{+} 44} \\
{[\mathrm{M}-\mathrm{CO}]^{+} 81}\end{array}$ \\
\hline 3 & {$\left[\mathrm{M}-\mathrm{C}_{4} \mathrm{H}_{4} \mathrm{~N}\right]^{+}(\mathrm{a})$} & 98 & 100 & 60 & 14 & 22 & 0.14 & 0.23 & $\begin{array}{l}{[\mathrm{M}-\mathrm{HCO}]^{+} 24} \\
{\left[\mathrm{M}-\mathrm{H}^{+} 29\right.}\end{array}$ \\
\hline 4 & {$\left[\mathrm{M}-\mathrm{C}_{4} \mathrm{H}_{4} \mathrm{~N}\right]^{+}(\mathrm{a})$} & 49 & 100 & 42 & 5 & $<1$ & 0.05 & 0.04 & $\begin{array}{l}{[M-H]^{+} 4} \\
{[M-H]^{+} 5}\end{array}$ \\
\hline 5 & {$\left[\mathrm{M}-\mathrm{C}_{3} \mathrm{H}_{3} \mathrm{~N}_{2}\right]^{+}$(a) } & 32 & 100 & 69 & $<1$ & 2 & $<0.01$ & 0.01 & $\begin{array}{l}{[\mathrm{M}-\mathrm{CO}]^{+} 21} \\
{[\mathrm{M}-\mathrm{H}]^{+} 9}\end{array}$ \\
\hline 6 & {$\left[\mathrm{M}-\mathrm{C}_{3} \mathrm{H}_{3} \mathrm{~N}_{2}\right]^{+}(\mathrm{a})$} & 24 & 100 & 72 & $<1$ & 2 & $<0.01$ & 0.01 & $\begin{array}{l}{[\mathrm{M}-\mathrm{CO}]^{+} 21} \\
{[\mathrm{M}-\mathrm{H}]^{+} 10}\end{array}$ \\
\hline 7 & {$[\mathrm{M}]^{+\cdot}$} & 100 & 96 & 54 & 55 & 2 & 0.57 & 0.38 & {$[\mathrm{M}-\mathrm{CO}]^{+} 15$} \\
\hline 8 & {$\left[M-\mathrm{C}_{6} \mathrm{H}_{5}\right]^{+}(b)$} & 82 & 36 & 36 & 100 & 6 & 2.78 & 1.47 & $\begin{array}{l}{[\mathrm{M}-\mathrm{H}]^{+} 11} \\
{[\mathrm{M}-\mathrm{CO}]^{+} 6}\end{array}$ \\
\hline 9 & {$\left[\mathrm{M}-\mathrm{C}_{6} \mathrm{H}_{5}\right]^{+}(b)$} & 87 & 15 & 35 & 100 & 22 & 6.67 & 2.44 & $\begin{array}{l}{[\mathrm{M}-\mathrm{H}]^{+} 32} \\
{[\mathrm{M}-\mathrm{CO}]^{+} 8} \\
{[\mathrm{M}-\mathrm{OH}]^{+} 11}\end{array}$ \\
\hline
\end{tabular}

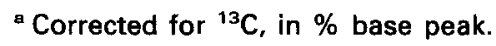

Table 2. Ionization energies $I(M)$ and appearance energies $A(a)$ and $A(b)$ from molecular ions of benzoyl hetarenes

\begin{tabular}{cccccc}
\hline Compound & $I(M)^{\mathrm{a}}$ & $\mathrm{A}(\mathrm{a})^{\mathrm{b}}$ & $\mathrm{A}(\mathrm{b})$ & $\mathrm{A}(\mathrm{a})-I(\mathrm{M})$ & $\mathrm{A}(\mathrm{b})-I(\mathrm{M})$ \\
$\mathbf{1}$ & 9.4 & $12.00^{5}$ & - & 2.6 & - \\
2 & 9.1 & 11.7 & - & 2.6 & - \\
3 & 9.6 & 11.7 & - & 2.1 & - \\
4 & 9.6 & 10.8 & - & 1.2 & - \\
$\mathbf{5}$ & 9.4 & 10.8 & - & 1.4 & - \\
6 & 9.4 & 10.7 & - & 1.3 & - \\
7 & 9.1 & 12.3 & 12.4 & 3.2 & 3.1 \\
$\mathbf{8}$ & 9.2 & 12.0 & 11.8 & 2.8 & 2.6 \\
9 & 8.7 & 13.1 & 12.2 & 4.4 & 3.5 \\
\hline
\end{tabular}

$\mathrm{eV}, \pm 0.1 \mathrm{eV}$ reference benzene $I\left(\mathrm{C}_{6} \mathrm{H}_{6}\right)=9.25 \mathrm{eV}^{6}$

$\mathrm{b} \mathrm{eV}, \pm 0.1 \mathrm{eV}$, reference benzene $l\left(\mathrm{C}_{6} \mathrm{H}_{6}\right)=9.25 \mathrm{eV}^{6}$

small intensities of ions $b$ in the mass spectra of benzoyl pyridines have been explained by the electron deficiency of the pyridyl group. ${ }^{4}$ By a similar argument the increasing intensity of ions $b$ in the mass spectra of 7,8 and 9 is explained by increasing electron density in the hetaryl groups. Figure 1 shows that there is an inverse correlation with the $\pi$-electron density ${ }^{7}$ at the carbon atom of the hetarene substituted with the benzoyl group, and the intensity of the benzoyl ions $a$ relative to the intensity of the molecular ions (i.e. $\left.Z(a)=[a] /\left[\mathrm{M}^{+*}\right]\right) .^{2}$ There exists also a good linear correlation between the $Z(a)$-values and the chemical shift in ${ }^{13} \mathrm{CNMR}$ of the $\mathrm{C}$ atom ${ }^{8}$ carrying the benzoyl group, with the exception of 7 , but much scattering is observed with respect to the total electron density ${ }^{7}$ at that $\mathrm{C}$ atom.

\section{Substituted 2-benzoyl pyridines and 2-benzoyl pyr- roles}

The effect of substituents on the phenyl group of 2 on the ionization energy (Table 3 ) follows the effects of substituents on the ionization energy of monosubstituted benzenes, given by the $\sigma_{\mathrm{IP}}{ }^{+}$-constants of Bentley and Johnstone ${ }^{9}$ (Fig. 2). The position of the substituent relative to the pyridoyl group has only a small effect, even if the substituent is in the ortho position.

The slope of the regression line is 0.83 , a typical value for benzene derivatives. ${ }^{9}$ The effect of substituents at the phenyl group of 9 (Table 5) appears to be somewhat smaller, probably due to a better delocalization of the positive charge in the molecular ions into the electron rich pyrrole group of 9 . The effect of electron donating substituents at the pyridyl group of 2 (Table 4), however, depends on the position and is much smaller, especially at position 4 , para to the nitrogen atom. Obviously much of the electron donating ability of these substituents is cancelled by the electron deficiency of the pyridine nucleus.

The appearance energies $A(a-X)$ of substituted benzoyl ions in the mass spectra of phenyl substituted 2 (Table 3 ) are influenced by the type and position of the substituent and follow the $\sigma^{+}$-constants of Brown ${ }^{10}$ as expected (Fig. 3). However, no relationship to $\sigma_{\mathrm{IP}}{ }^{+}-$or $\sigma$-constants is observed for the substituent effect on the $Z(a)$-values (Table 3 , right-hand

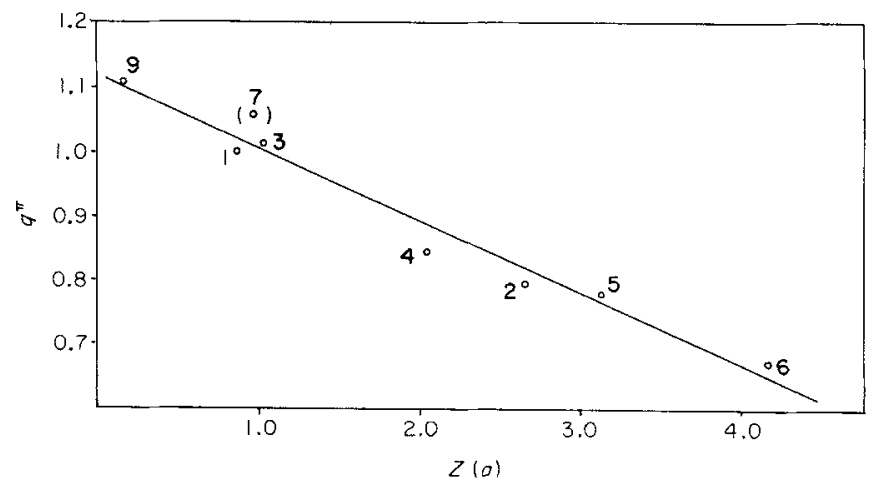

Figure 1. $\pi$-Electron densities and relative intensities of a for benzoyl hetarenes (1-9). 
Table 3. Substituent effects of phenyl substituted 2benzoyl pyridines $(2-X)$ on relative ionization energies $I(M)$ and relative appearance energies of substituted benzoyl ions $A(a-X)$

\begin{tabular}{lccc}
\hline $\mathrm{X}$ & $\Delta l(\mathrm{M})^{\mathrm{a}}$ & $\Delta \mathrm{A}(\mathrm{a}-\mathrm{X})^{\mathrm{b}}$ & $\mathrm{Z}(\mathrm{a})$ \\
$\mathrm{H}$ & - & - & 2.7 \\
$m-\mathrm{NO}_{2}$ & +0.58 & +0.7 & 4.3 \\
$p-\mathrm{NO}_{2}$ & +0.56 & +0.8 & 1.8 \\
$m-\mathrm{CF}_{3}$ & +0.40 & +0.5 & 2.8 \\
$m-\mathrm{Cl}$ & +0.04 & +0.1 & 2.0 \\
$p-\mathrm{Cl}$ & +0.0 & +0.1 & 2.3 \\
$o-\mathrm{F}$ & +0.02 & - & - \\
$o-\mathrm{CH}_{3}$ & -0.35 & - & - \\
$m-\mathrm{OCH}_{3}$ & -0.60 & -0.3 & 1.6 \\
$p-\mathrm{OCH}_{3}$ & -0.65 & -0.8 & 3.1 \\
$o-\mathrm{NH}_{2}$ & -1.19 & +0.4 & 1.1 \\
$m-\mathrm{NH}_{2}$ & -1.17 & -0.4 & 1.2 \\
$p-\mathrm{NH}_{2}$ & -1.07 & -1.4 & 2.9 \\
$p-\mathrm{NC}_{2}\left(\mathrm{CH}_{3}\right)_{2}$ & -1.32 & -1.6 & 2.0 \\
\hline
\end{tabular}

$I(2-X)-I(2) ; \mathrm{eV} ; \pm 0.05 \mathrm{eV}$.

${ }^{b} A(a-X)_{2-x}-A(a)_{2} ; e V ; \pm 0.1 \mathrm{eV}$.

Table 4. Substituent effects of pyridyl substituted 2-benzoyl pyridines $(2-X)$ on relative ionization energies $I(M)$ and relative appearance energies of substituted benzoyl ions $\mathbf{A}(a-X)$

\begin{tabular}{lccc}
\hline $\mathrm{X}$ & $\Delta(\mathrm{M})^{\mathrm{a}}$ & $\Delta \mathrm{A}(\mathrm{a})^{\mathrm{b}}$ & $\mathrm{Z}(\mathrm{a})$ \\
$\mathrm{H}$ & - & - & 2.6 \\
$3-\mathrm{CH}_{3}$ & -0.37 & +0.8 & 6.7 \\
$4-\mathrm{CH}_{3} \mathrm{O}$ & 0.00 & +1.2 & 2.3 \\
$5-\mathrm{CH}_{3} \mathrm{O}$ & -0.17 & +0.7 & 1.3 \\
$3-\mathrm{NH}_{2}$ & -0.72 & +0.9 & 1.2 \\
$4-\mathrm{NH}_{2}$ & -0.10 & +1.3 & 1.7 \\
$4-\mathrm{N}_{2}\left(\mathrm{CH}_{3}\right)_{2}$ & -0.89 & +1.4 & 0.6 \\
\hline
\end{tabular}

a $/\left(2-X^{\prime}\right)-1(2) ; \mathrm{eV} ; \pm 0.05 \mathrm{eV}$.

$A(a)_{2-X}-A(a)_{2} ; E V ; \pm 0.1 \mathrm{eV}$.

Table 5. Substituent effects of phenyl substituted 2-benzoyl pyrroles (9-X) on relative ionization energies $I(M)$ and relative appearance energies of pyrrole ions $\boldsymbol{A}(\boldsymbol{b})$

\begin{tabular}{lccll}
\hline$x$ & $\Delta I(M)^{a}$ & $\Delta A(M)^{b}$ & $Z(a)$ & $Z(b)$ \\
$\mathrm{H}$ & - & - & 0.18 & 1.16 \\
$m-\mathrm{NO}_{2}$ & +0.4 & 0.0 & 0.06 & 1.85 \\
$p-\mathrm{NO}_{2}$ & +0.4 & +0.2 & 0.11 & 2.45 \\
$m-\mathrm{Cl}$ & +0.1 & -0.2 & 0.19 & 1.81 \\
$p-\mathrm{Cl}$ & +0.1 & -0.1 & 0.23 & 1.20 \\
$m-\mathrm{OCH}_{3}$ & -0.4 & -0.1 & 0.19 & 1.14 \\
$\mathrm{p}-\mathrm{OCH}_{3}$ & -0.3 & -0.6 & 0.46 & 0.44 \\
\hline
\end{tabular}

a $/(9-X)-1(9) ; \mathrm{eV} ; \pm 0.05 \mathrm{eV}$.

${ }^{b} A(b)_{9-x}-A(b)_{9} ; \mathrm{eV} ; \mathrm{eV} ; \pm 0.1 \mathrm{eV}$.

column), and this is also observed for $Z(a)$-values calculated from low voltage mass spectra. The $Z(a)$ values mainly reflect the different mechanisms of the substituent effects on molecular and fragment ions, being dependent on position only in the latter case.
Hence the activation energies for the formation of $a-\mathrm{X}$ and correspondingly the $Z(a)$-values vary with the position of the substituent (see Table $3, m-\mathrm{NO}_{2}$ and $p-\mathrm{NO}_{2} ; m-\mathrm{OCH}_{3}$ and $p-\mathrm{OCH}_{3} ; m-\mathrm{NH}_{2}$ and $p-$ $\mathrm{NH}_{2}$ ).

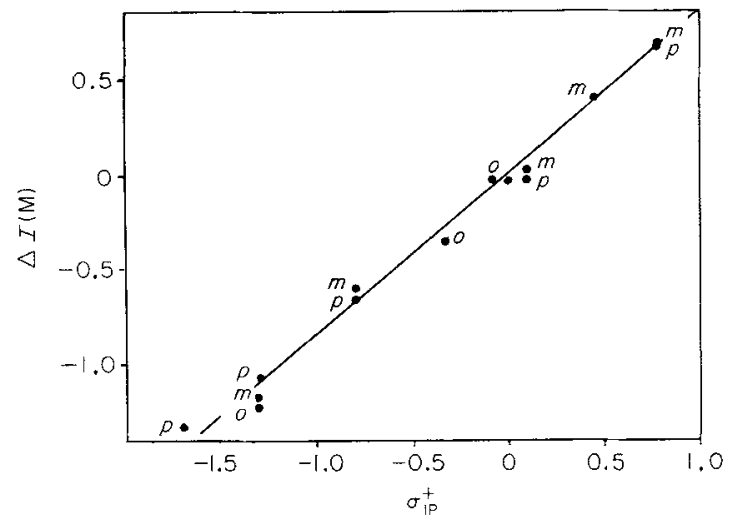

Figure 2. Substituent effects on ionization energies $/(M)$ of phenyl substituted 2-benzoyl pyridines.

The pyridoyl ions $b$ are observed in the mass spectra of 2-benzoyl pyridines, substituted at the phenyl group, with abundances of less than $3 \%$, even in the case of the nitro derivatives. Obviously more than one electron withdrawing substituent is needed to reduce the electron density of the phenyl group to the level of the pyridine nucleus and to reverse the charge retention by the different fragments of the two $a$-cleavages at the carbonyl group. Similarly, no pyridoyl ions (substituted $b$ ions) are found in the mass spectra of 2-benzoyl pyridines, substituted with electron donating groups at the pyridyl group, in spite of a considerable increase of $A(a)$, the ions formed by the competing $\alpha$-cleavage (Table 4 ). The activation energies for the formation of $a$ increase to $0.9-1.2 \mathrm{eV}, 1.4-1.6 \mathrm{eV}$ and $2.3 \mathrm{eV}$, respectively, by $\mathrm{CH}_{3} \mathrm{O}, \mathrm{NH}_{2}$ and $\left(\mathrm{CH}_{3}\right)_{2} \mathrm{~N}$ substituents at the pyridine group. Nevertheless, this increase in the activation energy of the otherwise favoured fragmentation process opens new reaction channels (loss of $\mathrm{H}, \mathrm{CO}, \mathrm{CHO}$ and the substituent) to the molecular ions of $\mathbf{2}$ rather than shifting the fragmention to the second $\alpha$-cleavage and the formation of pyridoyl ions $b$.

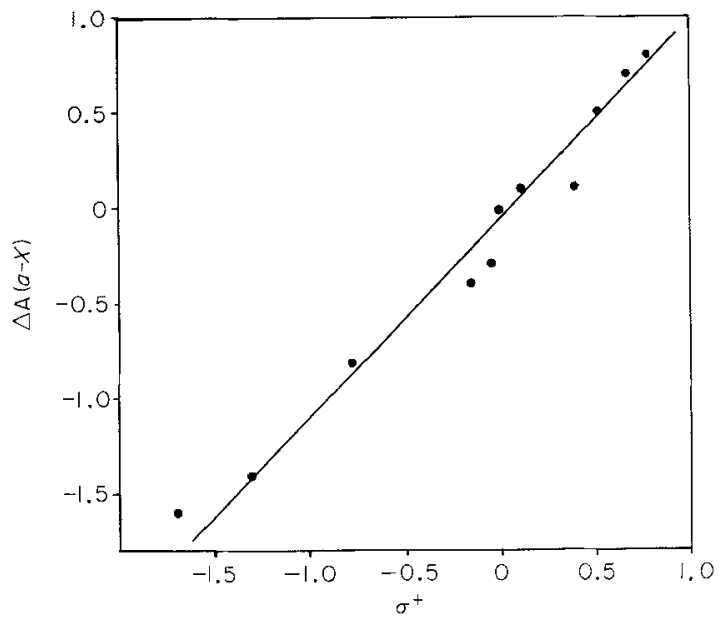

Figure 3. Substituent effects on appearance energies $A(X-a)$ of substituted benzoyl ions in 2-benzoyl pyridines. 


\section{CONCLUSION}

The mass spectra of benzoyl hetarenes contain ions resulting from the $\alpha$-cleavages at the carbonyl group of the molecular ions, as expected. The competition between both $\alpha$-cleavage processes seems to be governed by the relative electron density at the two $\mathrm{C}$ atoms, linked to the carbonyl group. This is indicated by an inverse correlation between the relative intensity ( $Z(a)$-values) of the benzoyl ions and the $\pi$-electron density. No simple correlation between substituent effects and ion intensities is observed in the mass spectra of substituted 2-benzoyl pyridines 2 and of substituted benzoyl pyrroles 9 , again showing the limited success of this approach. Good correlations, however, are found between $I(M)$ of substituted 2benzoyl pyridines and ${\sigma_{\mathrm{IP}}}^{+}$-values ${ }^{9}$ and $A\left(\mathrm{~F}^{+}\right)$of substituted benzoyl ions from these compounds and $\sigma^{+}$-values, ${ }^{10}$ respectively. Since the variations of ion intensities reflect the variations of the activation energies, expressed as the difference $A\left(F^{+}\right)-I(M)$, the determination of $I(M)$ and $A\left(F^{+}\right)$is certainly the method of choice for an investigation of substituent effects in mass spectra.

\section{EXPERIMENTAL}

The electron impact mass spectra were obtained with a $\mathrm{CH} 7$ mass spectrometer, Varian MAT Bremen. Ex- perimental conditions: accelerating voltage $3 \mathrm{kV}$, electron energy $70 \mathrm{eV}$, electron emission $2 \mathrm{~mA}$, ion source temperature c. $150^{\circ} \mathrm{C}$, direct insertion of the sample and sample temperature $<60^{\circ} \mathrm{C}$. The ion efficiency curves for all compounds were measured on the same instrument under similar conditions (however, electron emission $50 \mu \mathrm{A}$ ). The measurements of substituted 2-benzoyl pyridines were repeated with a modified MM 12 B mass spectrometer, Vacuum Generators, Altrincham. Experimental conditions: accelerating voltage $4 \mathrm{kV}$, electron emission $20 \mu \mathrm{A}$, repeller potential $0 \mathrm{~V}$, ion source temperature $150-$ $200^{\circ} \mathrm{C}$ and direct insertion of the sample. This mass spectrometer is equipped with a special electronic device allowing the simultaneous measurement of eight ion efficiency curves by switching the magnet current to the appropriate peaks ( $10 \mathrm{~s}$ for the complete cycle) and lowering the electron energy by preselected steps after each cycle. Benzene $(I(\mathrm{M})=$ $9.25 \mathrm{eV}^{6}$ ) was introduced simultaneously with each sample as a reference. The ionization energies $I(\mathrm{M})$ and appearance energies $A\left(\mathrm{~F}^{+}\right)$were evaluated from the ion efficiency curves by the semi-log plot method. ${ }^{11}$ The values given in Tables $2-5$ are the mean of at last three determinations.

2-, 3- and 4-benzoyl pyridine are commercially available (Fa. Merck) and were used without further purification. The other 2-benzoyl hetarenes and the substituted 2-benzoyl pyridines were synthesized according to the literature. ${ }^{12}$

\section{REFERENCES}

1. Part XXIV: Mechanisms of Mass Spectrometric Fragmentation Reactions. Part XXIII: B. Schaldach and H. F. Grützmacher, Int. J. Mass Spectrom. Ion Phys. 31, 271 (1979).

2. (a) M. M. Bursey and F. W. McLafferty, J. Am. Chem. Soc. 88, 529 (1966); (b) M. M. Bursey, Org. Mass Spectrom. 1, 31 (1968); (c) P. Krenmayr, R. Heller and K. Varmuza, Org. Mass Spectrom. 9, 998 (1974); (d) R. Heller, P. Krenmayr and K. Varmuza, Org. Mass Spectrom. 9, 1134 (1974); (e) R. Heller, K. Varmuza and P. Krenmayr, Monatsh. Chem. 105, 787 (1974).

3. M. M. Bursey and C. E. Twine Jr, J. Org. Chem. 36, 137 (1971).

4. (a) E. V. Brown and M. B. Shambhu, Org. Mass Spectrom. 6. 479 (1972); (b) U. Herzig, K. Varmuza and P. Krenmayr, Monatsh. Chem. 108, 191 (1977).

5. (a) H. F. Grützmacher, H. Kuschel and P. Adamietz, Adv. Mass Spectrom. 5, $654(1971)$; (b) N. G. Keats, L. A. Summers, J. Heterocycl. Chem. 13, 1289 (1976).

6. (a) H. M. Rosenstock, K. Draxl, B. W. Steiner and J. T. Herron, J. Phys. Chem. Ref. Data 6, Suppl. No. 1 (1977); (b) D. Stefanović and H. F. Grützmacher Org. Mass Spectrom. 9, 1052 (1974).
7. (a) R. J. Pugmire and D. M. Grant, J. Am. Chem. Soc. 90, 697 (1968); (b) R. J. Pugmire and D. M. Grant, J. Am. Chem. Soc. 90, 4232 (1968).

8. G. C. Levy and G. L. Nelson, Carbon-13 Nuclear Magnetic Resonance for Organic Chemists, Wiley-Interscience, New York (1972).

9. T. W. Bentley and R. A. W. Johnstone, J. Chem. Soc. B 263 (1971).

10. H. C. Brown and Y. Okamoto, J. Am. Chem. Soc. 80, 4979 (1958).

11. F. P. Lossing, A. N. Tickner and W. A. Bryce, J. Chem. Phys. 19, 1254 (1951).

12. (a) H. Gilman, S. M. Spatz, J. Org. Chem. 16, 1485 (1951); (b) N. H. Cantwell, E. V. Brown, J. Am. Chem. Soc. 75, 1489 (1953); (c) Org. Synth. 12, 62 (1932).

Received 1 May 1979; accepted 25 June 1979

(C) Heyden \& Son Ltd, 1979 